\title{
Laparoscopic Petersen's Hernia Reduction Was Associated With A Better Clinical Course Than Open Reduction After Gastrectomy: A Multicenter Observational Cohort Study
}

\section{Jae-Seok Min}

Dongnam Institute of Radiological and Medical Sciences

Kyung Won Seo

Kosin University Gospel Hospital

Sangho Jeong ( $\sim$ jshgnu@gmail.com )

Gyeongsang National University Graduate School of Medicine https://orcid.org/0000-0001-9061-6236

Ki Hyun Kim

Kosin University Gospel Hospital

Ji-ho Park

Gyeongsang National University Hospital

Ki Young Yoon

Kosin University Gospel Hospital

Tae-Han Kim

gyeongsang national university changwon hospital

Eun-Jung Jung

Gyeongsang National University

Young-tae Ju

Gyeongsang National University

Chi-Young Jeong

Gyeongsang National University

Ju-Yeon Kim

Gyeongsang National University

Young-Joon Lee

Gyeongsang National University

\section{Research article}

Keywords: Petersen's hernia, internal hernia, laparoscopy, gastric neoplasm

Posted Date: November 13th, 2020 
DOI: https://doi.org/10.21203/rs.3.rs-103557/v1

License: (c) (1) This work is licensed under a Creative Commons Attribution 4.0 International License. Read Full License

Version of Record: A version of this preprint was published at BMC Surgery on April 15th, 2021. See the published version at https://doi.org/10.1186/s12893-021-01200-8. 


\section{Abstract}

Background The aim of this multicenter cohort study was to compare the clinical courses between open and laparoscopic Petersen's hernia $(\mathrm{PH})$ reduction.

Materials and method We retrospectively collected the clinical data of patients who underwent $\mathrm{PH}$ repair surgery after gastrectomy for gastric cancer from 2015-2018. Forty patients underwent $\mathrm{PH}$ reduction operations that were performed by six expert surgeons at four hospitals. Among the 40 patients, 15 underwent laparoscopic $\mathrm{PH}$ reduction (LPH), and 25 underwent open $\mathrm{PH}$ reduction $(\mathrm{OPH})$, including 4 patients who underwent $\mathrm{LPH}$ but required conversion to $\mathrm{OPH}$.

Results We compared the clinical factors between the LPH and OPH groups. In the clinical course, we found no differences in operation times or intraoperative bowel injury, morbidity, or mortality rates between the two groups ( $p>0.05$ ). However, the number of days on a soft fluid diet (OPH vs. LPH; 5.8 vs. 3.7 days, $p=0.03$ ) and length of hospital stay ( 12.6 vs. 8.2 days, $p=0.04)$ were significantly less in the LPH group than the $\mathrm{OPH}$ group. Regarding postoperative complications, the $\mathrm{OPH}$ group had a case of pneumonia and sepsis with multi-organ failure, which resulted in mortality. In the LPH group, one patient experienced recurrence and required reoperation for $\mathrm{PH}$.

Conclusion Laparoscopic $\mathrm{PH}$ reduction was associated with a faster postoperative recovery period than open $\mathrm{PH}$ reduction, with a similar incidence of complications. The laparoscopic approach should be considered an appropriate strategy for $\mathrm{PH}$ reduction.

\section{Background}

Internal hernia can occur as a result of the artificial mesenteric opening left by entero-entero anastomosis or Petersen's space after a Roux-en-Y anastomosis. Petersen's hernia $(\mathrm{PH})$ is rare but potentially fatal complication that can develop as the result of strangulation or perforation of a herniated small bowel [1]. Therefore, $\mathrm{PH}$ should be treated as soon as possible following its detection. Recently, it was reported that the incidence of internal hernia was higher after laparoscopic gastrectomy than after open gastrectomy, possibly because of poor adhesion after laparoscopic surgery [2].

Laparoscopic surgery is a recommended treatment modality for cancer (stomach, colon, liver, biliary) because it is associated with faster postoperative recovery, a lower incidence of complications, and better quality of life outcomes of patients than open surgery [3-8]. Laparoscopic internal hernia reduction in the small segment of the small bowel has been reported, but the surgical outcomes associated with laparoscopic $\mathrm{PH}$ reduction have not been reported $[9,10]$. The aim of this multicenter cohort study was to compare the clinical courses between open and laparoscopic $\mathrm{PH}$ reductions. This is the first report involving a large multicenter cohort of gastric cancer patients after gastrectomy.

\section{Methods}


A retrospective observational study was designed and carried out according to the principles of the Declaration of Helsinki, 1989. This study was approved by the institutional review board (approval number of first author's institution, IRB-D-1909-009-002, and corresponding author's institution, GNUHIRB-2020-3-32).

\section{Patients}

We retrospectively collected the clinical data of patients who underwent $\mathrm{PH}$ repair surgery after gastrectomy for gastric cancer from 2015-2018. Between 2015 and 2018, a total of $40 \mathrm{PH}$ operations were performed at four hospitals (Changwon \& Jinju Gyeongsang National University Hospitals, Dongnam Institute of Radiological and Medical Sciences, and Kosin University Gospel Hospital). Among the 40 patients, 15 underwent laparoscopic $\mathrm{PH}$ reduction (LPH), 4 underwent LPH with open conversion, and 21 underwent open $\mathrm{PH}$ reduction (OPH). Therefore, a total of 25 patients underwent OPH (Fig. 1).

Six expert surgeons in laparoscopic gastrectomy have been meeting and sharing their experiences with LPH since 2015. All the surgeons were specialists in gastric cancer surgery with experience in performing more than 200 laparoscopic gastrectomies.

The data of patients who underwent surgery from 2015 to 2018 for intestinal obstruction caused by PH were collected. The inclusion criteria for this study were as follows: 1) previous radical surgery for histologically proven primary gastric adenocarcinoma; and 2) no evidence of other distant metastases.

We collected data regarding the operation, postoperative complications, and course by retrospective chart review after surgery. We compared the past gastric cancer surgery method, TNM stage, surgical information, and postoperative course.

\section{Operations}

Decision of open vs. laparoscopic reduction

The decision to perform laparoscopic reduction or open reduction was made by the surgeon after determining whether the patient had undergone laparoscopic surgery in the past, whether the patient presented with poor vital signs in the emergency room, and the statuses of bowel edema and dilation in the abdominal cavity on abdominal CT.

Open reduction The operation began with an incision at the site of the previous incision, and an additional incision was made if necessary. During the incision, adhesiolysis was carefully performed to prevent injury to organs with adhesions. After the abdominal wall was opened, the viability of the herniated small bowel was determined. If the herniation direction was easy to detect, surgery was performed immediately. However, it was sometimes difficult to determine the correct direction of herniation. In these cases, we performed the following. First, we identified the ileocolic valve and fully reduced the herniated bowel. After complete reduction, we checked the status of bowel perforation and 
necrosis. If the bowel was not viable even after reduction, we resected the damaged small bowel segment. We closed Petersen's space with non-absorbable sutures.

Laparoscopic reduction The first trocar was inserted inferior to the umbilicus or in the lower abdomen area by an open method with a new incision. Mostly, we performed the reduction using three or four trocars. The intra-abdominal reduction process was the same as that performed in the open method. However, it was difficult to determine the correct direction of herniation with a laparoscope. Therefore, we first identified the ileocolic valve and fully reduced the herniated bowel by pulling it out. After complete reduction, we checked the status of bowel perforation and necrosis. If the bowel was not viable even after reduction, we resected the damaged small bowel segment. We closed Petersen's space with nonabsorbable sutures (supplement Video).

The possibility of damage or bleeding in the small intestine is higher during laparoscopic hernia reduction than during open reduction due to forceful pulling of laparoscopic graspers. We recommend open conversion for patients with a poor pneumoperitoneum condition or severely damaged bowel, as reduction is difficult due to severe bowel edema.

\section{Statistical analysis}

We used SPSS Statistics version 24 (IBM SPSS, Inc., Chicago, IL, USA) for the statistical analyses. Continuous data were compared using unpaired Student's t-test and are presented as means \pm standard deviations; non-continuous variables were assessed with the chi square test. In all analyses, $p$ values less than 0.05 were considered statistically significant.

\section{Results}

\section{Patient demographics}

Between 2015 and 2018, a total of $40 \mathrm{PH}$ operations were performed at the four hospitals. The patient demographics are described in Table 1. The average age of patients was 63.9 years old, and the ratio of men to women was 4:1 (32:8). The TNM stage at past gastrectomy was as follows: the highest was stage I, which accounted for $60 \%$; stage II accounted for $22.5 \%$; stage III was the lowest and accounted for $5 \%$; and unknown TNM stage accounted for $12.5 \%$. Regarding past surgeries, there were 11 total gastrectomies (TGs), 24 distal gastrectomies (DGs) and 2 proximal gastrectomies (PGs). The past surgical methods comprised open methods in 28 cases, laparoscopic methods in 7 cases, and unknown methods in five cases. The mean period between operations was 28.2 months. The mean duration between the presentation of pain and hernia operation was 51.3 hours. 
Table 1

Patients demographics

\section{Factors}

Age (years)

Sex

TNM stage of Gastric cancer*

(n)

Previous operation

Previous operation

Previous op Approach method

Open gastrectomy
Laparoscopy assisted
unknown

Periods between previous operation (Month)

Time duration between pain to hernia operation (hour)

Approach method

Open reduction

Laparoscopic reduction

Open conversion of laparoscopic reduction

Operation time

Small bowel injury during reduction

Hospital stay (day)

Morbidity

\section{Value}

$63.9 \pm 12.1$

$32(80 \%)$

$8(20 \%)$

$24(60 \%)$

$9(22.5 \%)$

2 (5\%)

$5(12.5 \%)$

11 (27.5\%)

$17(42.5 \%)$

2 (5\%)

$5(12.5 \%)$

$2(5 \%)$

$3(7.5 \%)$

$28(70 \%)$

$7(17.5 \%)$

5 (12.5\%)

$28.2 \pm 45.7$

$51.3 \pm 96.4$

21 (52.5\%)

15 (37.5\%)

$4(10.0 \%)$

$79.5 \pm 25.1$ minutes

$4(10 \%)$

$10.9 \pm 6.8$

$4(10 \%)$

*, AJCC TNM stage 8th edition, GIST, gastrointestinal stromal tumor, TG, total gastrectomy, RNY, Rouxen $Y$, EJ, esophagojejunostomy, B II, Billroth II, GJ, gastrojejunostomy, PG, proximal gastrectomy 


\section{Factors}

Value

Mortality

$1(2.5 \%)$

*, AJCC TNM stage 8th edition, GIST, gastrointestinal stromal tumor, TG, total gastrectomy, RNY, Rouxen Y, EJ, esophagojejunostomy, B II, Billroth II, GJ, gastrojejunostomy, PG, proximal gastrectomy

Regarding the approach for $\mathrm{PH}$ reduction, 15 patients underwent $\mathrm{LPH}, 4$ patients underwent LPH with open conversion, and 21 underwent OPH. Therefore, a total of 25 were OPH (Fig. 1). The causes of open conversion were difficulty in creating a pneumoperitoneum $(n=2)$ and difficulty in laparoscopic reduction due to small bowel and mesentery thickness $(n=2)$. The mean operation time was 79.5 minutes; 4 patients experienced small bowel injury during reduction. The mean hospital stay was 10.9 days. The morbidity rate was $10 \%$ ( 4 cases), and there was one mortality.

\section{Comparison of clinical factors between the LPH group and the OPH group}

We compared the clinical factors between the $\mathrm{LPH}$ and $\mathrm{OPH}$ groups. We found that the OPH group was older (68.8 years) than the LPH group $(55.7$ years) $(p<0.001)$ and had a higher C-reactive protein (CRP) level (OPH vs. $\mathrm{LPH} ; 5.5$ vs. $0.72, \mathrm{p}=0.03)$. However, there were no differences in sex, initial symptoms, duration between operations, TNM stage, previous operation, previous approach method, preoperative white blood cell (WBC) count, or erythrocyte sedimentation rate (ESR) $(p>0.05$, Table 2). 
Table 2

Clinicopathologic comparison between Laparoscopic reduction group (Laparo group) and open reduction group (Open group)

\begin{tabular}{|c|c|c|c|c|}
\hline \multicolumn{2}{|l|}{ Factors } & $\begin{array}{l}\text { Open group }(\mathrm{N}= \\
25)\end{array}$ & $\begin{array}{l}\text { Lapro group }(\mathrm{N}= \\
\text { 15) }\end{array}$ & $\begin{array}{l}P \\
\text { value }\end{array}$ \\
\hline \multicolumn{2}{|l|}{ Age (years) } & $68.8 \pm 10.4$ & $55.7 \pm 10.4$ & $\begin{array}{l}<.001 \\
0.00\end{array}$ \\
\hline \multirow[t]{2}{*}{ Sex } & Male & 19 & 13 & 0.68 \\
\hline & Female & 6 & 2 & \\
\hline \multirow[t]{3}{*}{ Initial symptom } & Nausea & 7 & 4 & 1.0 \\
\hline & Vomiting & 8 & 5 & 1.0 \\
\hline & Pain & 24 & 14 & 1.0 \\
\hline \multicolumn{2}{|c|}{ Periods between previous operation (month) } & $29.9 \pm 56.5$ & $25.4 \pm 20.2$ & 0.77 \\
\hline \multirow{4}{*}{$\begin{array}{l}\text { TNM stage of Gastric } \\
\text { cancer* }\end{array}$} & I & 14 & 10 & 0.13 \\
\hline & II & 4 & 5 & \\
\hline & III & 2 & 0 & \\
\hline & unknown & 5 & 0 & \\
\hline \multicolumn{2}{|c|}{$\begin{array}{l}\text { Time duration between pain to hernia operation } \\
\text { (hour) }\end{array}$} & $40.0 \pm 83.3$ & $70.7 \pm 116.4$ & 0.35 \\
\hline \multirow[t]{6}{*}{ Previous operation } & TG with RNY EJ & 7 & 4 & 0.50 \\
\hline & DG with B II & 10 & 7 & \\
\hline & DG with RNY & 1 & 1 & \\
\hline & $\begin{array}{l}\text { DG with uncut } \\
\text { RNY }\end{array}$ & 2 & 2 & \\
\hline & $\begin{array}{l}\text { PG with double } \\
\text { tract }\end{array}$ & 2 & 0 & \\
\hline & Unknown & 3 & 0 & \\
\hline \multirow{3}{*}{$\begin{array}{l}\text { Previous approach } \\
\text { method }\end{array}$} & Open & 15 & 13 & 0.20 \\
\hline & Laparoscopy & 6 & 1 & \\
\hline & unknown & 4 & 1 & \\
\hline
\end{tabular}

*, AJCC TNM stage 8th edition, GIST, gastrointestinal stromal tumor, TG, total gastrectomy, RNY, Rouxen Y, EJ, esophagojejunostomy, B II, Billroth II, PG, proximal gastrectomy, WBC, white blood cell, ESR, erythrocyte sedimentation rate, CRP, C-reactive protein 


\begin{tabular}{|lllll|}
\hline Factors & & $\begin{array}{l}\text { Open group }(\mathbf{N}= \\
\text { 25) }\end{array}$ & Lapro group $(\mathbf{N}=$ & $\begin{array}{l}\mathbf{P} \\
\text { value }\end{array}$ \\
\hline Preop Laboratory & WBC & $10,025 \pm 5.045$ & $8,546 \pm 2,768$ & 0.30 \\
\hline ESR & $23.7 \pm 25.2$ & $16.3 \pm 13.9$ & 0.39 \\
\hline CRP & $\mathbf{5 . 5 \pm 1 0 . 5}$ & $\mathbf{0 . 7 2} \pm \mathbf{1 . 1}$ & $\mathbf{0 . 0 3}$ \\
\hline $\begin{array}{l}\text { *, AJCC TNM stage 8th edition, GIST, gastrointestinal stromal tumor, TG, total gastrectomy, RNY, Roux- } \\
\text { en Y, EJ, esophagojejunostomy, B II, Billroth II, PG, proximal gastrectomy, WBC, white blood cell, ESR, } \\
\text { erythrocyte sedimentation rate, CRP, C-reactive protein }\end{array}$ & & \\
\hline
\end{tabular}

\section{Comparison of operations and postoperative clinical courses between the OPH group and LPH group}

We found no differences in operation time or intraoperative bowel injury, morbidity, or mortality rates ( $p$ > $0.05)$. However, the number of days on a soft fluid diet (OPH vs. LPH; 5.8 vs. 3.7 days, $p=0.03$ ) and length of hospital stay (12.6 vs. 8.2 days, $p=0.04$ ) were significantly less in the LPH group than in the $\mathrm{OPH}$ group (Table 3$)$.

Table 3

Comparisons of operation data and postoperative clinical courses between the open reduction group (Open group) and laparoscopic reduction group (Laparo group).

\begin{tabular}{|llll|}
\hline Clinical factor & Open group $(\mathbf{N}=\mathbf{2 5}, \%)$ & Lapro group (N=15, \%) & P value \\
\hline Operation time & $83.1 \pm 26.1$ & $73.6 \pm 23.1$ & 0.25 \\
\hline Bowel injury during operation & $2(8 \%)$ & $2(13.3 \%)$ & 0.62 \\
\hline SFD start day & $\mathbf{5 . 8} \pm 3.1$ & $3.7 \pm 2.1$ & 0.03 \\
\hline Hospital stay & $12.6 \pm 7.4$ & $\mathbf{8 . 2} \pm 4.9$ & 0.04 \\
\hline Morbidity & $2(8 \%)$ & $1(6.7 \%)$ & 1.0 \\
\hline Mortality & $1(4 \%)$ & 0 & 1.0 \\
\hline ASIS, anterior superior iliac spine, SMV, superior mesenteric vein & \\
\hline
\end{tabular}

\section{Postoperative Complications}

In $\mathrm{OPH}$ group, one case of pneumonia and one case of sepsis with multi-organ failure resulted in mortality. In the LPH group, one patients experienced recurrence of $\mathrm{PH}$ at postoperative day 8 , and he underwent a second reduction by the open method (Table 4). The patient was discharged 16 days after reoperation without other complications. 
Table 4

postoperative complications

\begin{tabular}{|lll|}
\hline Complications & Open group & Lapro group \\
\hline Pneumonia & 1 & 0 \\
\hline Sepsis with multi-organ failure & 1 & 0 \\
\hline Petersen's hernia recur & 0 & 1 \\
\hline
\end{tabular}

\section{Discussion}

The aim of this multicenter cohort study was to compare the clinical courses between open and laparoscopic PH reductions. The postoperative recovery course is generally better, and operative wounds are generally smaller with the laparoscopic approach than with open surgery. However, to the best of our knowledge, no one has reported the benefits of laparoscopic $\mathrm{PH}$ reduction. The present multicenter observational cohort study is the first to report the advantage of laparoscopic $\mathrm{PH}$ reduction in terms of postoperative recovery.

$\mathrm{PH}$ is a very rare disease that occurred in only $0.54 \%$ of patients who underwent gastrectomy for gastric cancer (2,417; the number of patients requiring PH reduction surgery was 13) between 2015 and 2018. In a previous study, the incidence of $\mathrm{PH}$ after gastrectomy was $0.42 \%$, which was similarly low compared to our data [2, 3]. For $\mathrm{PH}$ reduction surgery, the open method is the standard procedure due to the following: first, it is difficult to develop pneumoperitoneum due to bowel edema and bowel dilation in the abdominal cavity; second, bowel reduction is difficult due to bowel wall and mesentery edema, and usually the whole small bowel is herniated; third, experience in laparoscopic $\mathrm{PH}$ reduction is limited $[2,9,11]$. In our group, the first laparoscopic reduction was performed in 2014 in Kosin University Hospital; since then, gastric experts from the four centers share their experiences with laparoscopic $\mathrm{PH}$ reduction during regular meetings. Sharing their experiences facilitates the application of laparoscopic $\mathrm{PH}$ reduction because all surgeons are gastric cancer surgery specialists with experience in performing more than 200 laparoscopic gastrectomies.

Laparoscopic surgery has advantages. We found that the number of days on a soft fluid diet and postoperative hospital length of stay were significantly less in the laparoscopic reduction group than in the open group. The reason for the faster recovery is likely that laparoscopic surgery resulted in fewer operative wounds and less pain than open surgery. Additionally, if the bowels were not manipulated excessively by the surgeon during laparoscopy, a postoperative diet could be permitted quickly, causing a potential decrease in the length of hospital stay.

Recently, the application of the laparoscopic approach for primary gastrectomy has increased; however, one study reported the possibility of an increased incidence of internal hernia [2]. They reported that laparoscopic TG was associated with a higher incidence of internal hernia than open TG (4.5\%, 29/638 vs. $0.8 \%, 4 / 475)$, with the same results for laparoscopic DG compared with open DG (2.7\% vs. $0.9 \%)$. In 
the multivariate analysis, they found that non-closure of mesenteric defects, the laparoscopic approach, and a total laparoscopic approach were independent risk factors for internal hernia. We expected the incidence of $\mathrm{PH}$ to be higher in primary laparoscopic gastrectomy patients; however, the incidence of $\mathrm{PH}$ was higher in primary open gastrectomy patients. This may be because more patients underwent open gastrectomy than laparoscopic gastrectomy in the past. Even though there was only a small number of $\mathrm{PH}$ cases included in this study, interestingly, the laparoscopic or open primary approach for gastrectomy did not affect the incidence of $\mathrm{PH}$. In contrast, a recent study reported that closure of the mesenteric space $(5.5 \%)$ significantly decreased the cumulative incidence of reoperation for small bowel obstruction by internal hernia after surgery compared to no mesenteric closure (10.2\%) [12]. Therefore, to reduce postoperative complications, especially the incidence of internal hernia after gastrectomy surgery, the closure of mesenteric defects should be performed [2]. The centers included in this study routinely repair mesenteric defects after gastrectomy and have recently started performing closure of Petersen's space to prevent $\mathrm{PH}$.

In terms of postoperative complications, pneumonia generally occurs more frequently in patients who undergo open surgery; open surgery patients also experience more wound pain than patients who undergo minimally invasive surgery [7]. In this study, the one pneumonia patient was an 80-year-old individual who was at increased risk for postoperative complications due to age. In the laparoscopic group, a complication of internal hernia recurrence after reduction surgery was observed. This suggests that we need to close defects more carefully because reduction and closure after laparoscopic surgery is more difficult than after manual open surgery.

Despite the very low incidence of $\mathrm{PH}$, there were some limitations to our study, such as the small number of $\mathrm{PH}$ reduction surgeries especially laparoscopic reduction surgeries. The surgeons did not have extensive experience with the laparoscopic approach for $\mathrm{PH}$ reduction because it is not a common technique, and $\mathrm{PH}$ is a rare disease. Nevertheless, to the best of our knowledge, this is the first report comparing the surgical outcomes associated with open and laparoscopic approaches for PH reduction.

\section{Conclusions}

Laparoscopic $\mathrm{PH}$ reduction was associated with faster postoperative recovery and a similar incidence of complications compared with open surgery. The laparoscopic approach could be considered an appropriate strategy for $\mathrm{PH}$ reduction.

\section{Abbreviations}

$\mathrm{PH}$, Petersen's hernia; LPH, laparoscopic Petersen's hernia reduction; $\mathrm{OPH}$, open Petersen's hernia reduction; TG, total gastrectomy; DG, distal gastrectomy; PG, proximal gastrectomy; CRP, C-reactive protein; WBC, white blood cell; ESR, erythrocyte sedimentation rate (ESR)

\section{Declarations}




\section{Ethics Approval and Consent to Participate}

All procedures followed were in accordance with the ethical standards of the responsible committee on human experimentation (institutional and national) and with the Helsinki Declaration of 1964 and later versions. The exemption from informed consent requirement was permitted by Gyeongsang National University Hospital in Changwon (GNUCHIRB-202003032) and at the Dongnam Institute of Radiological and Medical Sciences in Busan, Korea Institutional Review Board (IRB-D-1909-009-002).

\section{Consent for publication}

Not Applicable.

\section{Availability of data and material}

Not Applicable.

\section{Competing Interests}

Dr. Jae-Seok Min, Kyung Won Seo, Ki Hyun Kim, Sang-Ho Jeong, Ji-ho Park, Ki Young Yoon, Tae-Han Kim, Eun-Jung Jung, Young-tae Ju, Chi-Young Jeong, Ju-Yeon Kim, Young-Joon Lee, and have no conflicts of interest or financial ties to disclose.

Funding Not Applicable.

\section{Author's contribution}

JSM-Conceptualization, Methodology, Validation, Investigation, Resources, Data Curation, Project administration, Writing; KWS-Conceptualization, Methodology, Investigation; SHJ-Conceptualization, Methodology, Investigation, Writing; JHP, KUY, THK-Investigation, Resources, Data collection; EJJ, YTJ, CYJ, JYK, YJL-Investigation, Data collection, project administration. All authors, JSM, KWS, SHJ, JHP, KUY, THK, EJJ, YTJ, CYJ, JYK, and YJL have read and approved the manuscript for publication.

\section{Acknowledgements}

No applicable

\section{References}

1. Petersen W (1900) Ueber darmveschlingung nach der gastro-enterostomie. Arch Klin Chir 62:94-114

2. Kang KM, Cho YS, Min SH, Lee Y, Park KB, Park YS, Ahn SH, Park DJ, Kim HH (2019) Internal hernia after gastrectomy for gastric cancer in minimally invasive surgery era. Gastric Cancer 22:1009-1015

3. Guideline Committee of the Korean Gastric Cancer Association DWG, Review P (2019) Korean

Practice Guideline for Gastric Cancer 2018: an Evidence-based, Multi-disciplinary Approach. J Gastric Cancer 19:1-48 
4. Kim W, Kim HH, Han SU, Kim MC, Hyung WJ, Ryu SW, Cho GS, Kim CY, Yang HK, Park DJ, Song KY, Lee SI, Ryu SY, Lee JH, Lee HJ, Korean Laparo-endoscopic Gastrointestinal Surgery Study G (2016) Decreased Morbidity of Laparoscopic Distal Gastrectomy Compared With Open Distal Gastrectomy for Stage I Gastric Cancer: Short-term Outcomes From a Multicenter Randomized Controlled Trial (KLASS-01). Ann Surg 263:28-35

5. Hu Y, Huang C, Sun Y, Su X, Cao H, Hu J, Xue Y, Suo J, Tao K, He X, Wei H, Ying M, Hu W, Du X, Chen P, Liu H, Zheng C, Liu F, Yu J, Li Z, Zhao G, Chen X, Wang K, Li P, Xing J, Li G (2016) Morbidity and Mortality of Laparoscopic Versus Open D2 Distal Gastrectomy for Advanced Gastric Cancer: A Randomized Controlled Trial. J Clin Oncol 34:1350-1357

6. Johansson M, Thune A, Nelvin L, Stiernstam M, Westman B, Lundell L (2005) Randomized clinical trial of open versus laparoscopic cholecystectomy in the treatment of acute cholecystitis. Br J Surg 92:44-49

7. Qaseem A, Snow V, Fitterman N, Hornbake ER, Lawrence VA, Smetana GW, Weiss K, Owens DK, Aronson M, Barry P, Casey DE, Jr., Cross JT, Jr., Fitterman N, Sherif KD, Weiss KB (2006) Risk assessment for and strategies to reduce perioperative pulmonary complications for patients undergoing noncardiothoracic surgery: a guideline from the American College of Physicians. Ann Intern Med 144:575-580

8. Veldkamp R, Kuhry E, Hop WC, Jeekel J, Kazemier G, Bonjer HJ, Haglind E, Påhlman L, Cuesta MA, Msika S, Morino M, Lacy AM (2005) Laparoscopic surgery versus open surgery for colon cancer: short-term outcomes of a randomised trial. Lancet Oncol 6:477-484

9. Sakamoto T, Kawarai Lefor A (2017) Laparoscopic Reduction and Closure of an Internal Hernia Secondary to Gynecologic Surgery. Case Rep Surg 2017:5948962

10. Goudsmedt F, Deylgat B, Coenegrachts K, Van De Moortele K, Dillemans B (2015) Internal hernia after laparoscopic Roux-en-Y gastric bypass: a correlation between radiological and operative findings. Obes Surg 25:622-627

11. Kojima K, Inokuchi M, Kato K, Motoyama K, Sugihara K (2014) Petersen's hernia after laparoscopic distal gastrectomy with Roux-en-Y reconstruction for gastric cancer. Gastric Cancer 17:146-151

12. Stenberg E, Szabo E, Agren G, Ottosson J, Marsk R, Lonroth H, Boman L, Magnuson A, Thorell A, Naslund I (2016) Closure of mesenteric defects in laparoscopic gastric bypass: a multicentre, randomised, parallel, open-label trial. Lancet 387:1397-1404

\section{Figures}




\section{- Four training hospital observational study \\ - Period : 2015-2018}

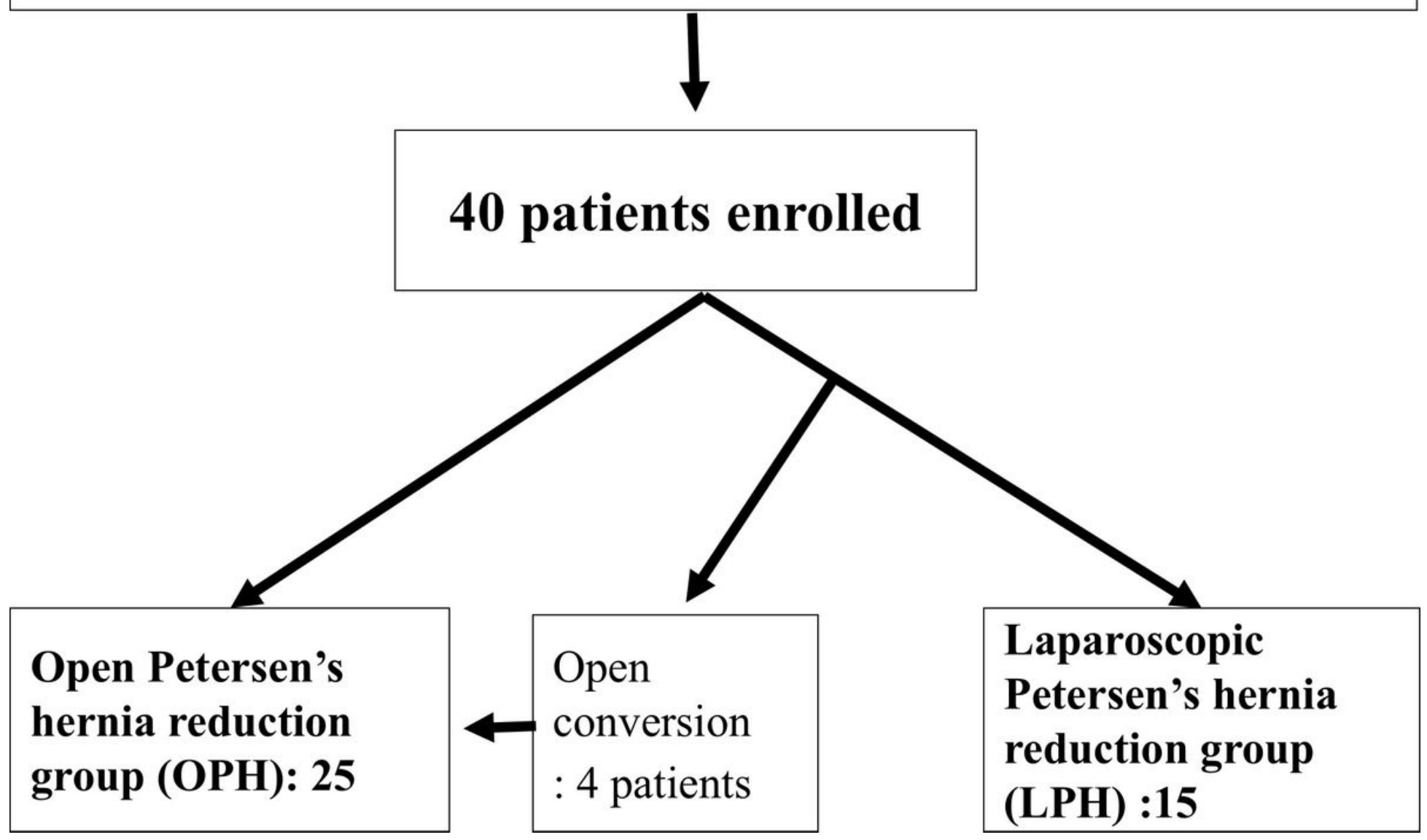

Figure 1

Diagram of patient enrollment

\section{Supplementary Files}

This is a list of supplementary files associated with this preprint. Click to download.

- SupplementvidoeLaparoPHreduction.mp4 